\title{
Computed tomography total airway count predicts progression to COPD in at-risk smokers
}

\author{
Miranda Kirby ${ }^{1,2}$, Benjamin M. Smith ${ }^{3,4,5}$, Naoya Tanabe $\mathbb{D}^{2}$, James C. Hogg ${ }^{2}$, Harvey O. Coxson ${ }^{2}$, \\ Don D. $\operatorname{Sin}^{2}$, Jean Bourbeau (10), and Wan C. $\operatorname{Tan}^{2}$ for the CanCOLD Collaborative Research Group \\ and the Canadian Respiratory Research Network
}

${ }^{1}$ Dept of Physics, Ryerson University, Toronto, ON, Canada. ${ }^{2}$ UBC Centre for Heart Lung Innovation, St Paul's Hospital, Vancouver, BC, Canada. ${ }^{3}$ Dept of Medicine, McGill University, Montreal, QC, Canada. ${ }^{4}$ Dept of Epidemiology, Biostatistics, and Occupational Health, McGill University, Montreal, QC, Canada. ${ }^{5}$ Dept of Medicine, Columbia University Medical Center, New York, NY, USA. ${ }^{6}$ Montreal Chest Institute of the Royal Victoria Hospital, McGill University Health Centre, Montreal, QC, Canada. ${ }^{7}$ Respiratory Epidemiology and Clinical Research Unit, Research Institute of McGill University Health Centre, Montreal, QC, Canada.

Corresponding author: Miranda Kirby (miranda.kirby@ryerson.ca)

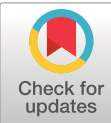

This version is distributed under the terms of the Creative Commons Attribution Non-Commercial Licence 4.0. For commercial reproduction rights and permissions contact permissions@ersnet.org

Received: 3 May 2021 Accepted: 7 July 2021

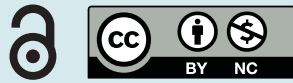

Shareable abstract (@ERSpublications)

Computed tomography (CT) total airway count (TAC) predicts incident COPD in at-risk smokers, indicating that smokers exhibit early airway remodelling prior to abnormal spirometry and that CT TAC is a potential tool to help identify smokers at increased risk of COPD https://bit.ly/2UTw314

Cite this article as: Kirby M, Smith BM, Tanabe N, et al. Computed tomography total airway count predicts progression to COPD in at-risk smokers. ERJ Open Res 2021; 7: 00307-2021 [DOI: 10.1183/ 23120541.00307-2021].

\section{Abstract}

There is limited understanding of how to identify people at high risk of developing COPD. Our objective was to investigate the association between computed tomography (CT) total airway count (TAC) and incident COPD over 3 years among ever-smokers from the population-based Canadian Cohort Obstructive Lung Disease (CanCOLD) study.

CT and spirometry were acquired in ever-smokers at baseline; spirometry was repeated at 3-year followup. CT TAC was generated by summing all airway segments in the segmented airway tree (VIDA Diagnostics, Inc.). CT airway wall area, wall thickness for a theoretical airway with $10 \mathrm{~mm}$ perimeter (Pi10), and low attenuation areas below $-856 \mathrm{HU}\left(\mathrm{LAA}_{856}\right)$ were also measured. Logistic and mixed effects regression models were constructed to determine the association for CT measurements with development of COPD and forced expiratory volume in $1 \mathrm{~s} /$ forced vital capacity $\left(\mathrm{FEV}_{1} / \mathrm{FVC}\right)$ decline, respectively.

Among 316 at-risk participants evaluated at baseline (65 \pm 9 years, $40 \%$ female, $18 \pm 19$ pack-years), incident COPD was detected in 56 participants (18\%) over a median $3.1 \pm 0.6$ years of follow-up. Among CT measurements, only TAC was associated with incident COPD ( $p=0.03)$, where a 1-sD decrement in TAC increased the odds ratio for incident COPD by a factor of two. In a multivariable linear regression model, reduced TAC was significantly associated with greater longitudinal $F E V_{1} / F V C$ decline $(p=0.03)$, but no other measurements were significant.

CT TAC predicts incident COPD in at-risk smokers, indicating that smokers exhibit early structural changes associated with COPD prior to abnormal spirometry.

\section{Introduction}

Smoking is an established risk factor for COPD, but only 25-30\% of smokers develop the irreversible airflow limitation that characterises COPD [1, 2]. In those smokers without COPD, up to 50\% report respiratory symptoms $[3,4]$, and $4 \%$ experience exacerbations, and these events are associated with the use of respiratory medications and self-perceived poor health outcomes [5]. Therefore, there is evidence that structural changes may precede the development of airflow limitation in smokers.

Evidence is mounting that smokers without airflow limitation have evidence of airway remodelling. Tobacco smoke has been shown to induce pro-inflammatory responses in the lungs and impairs innate 
defence mechanisms in smokers without COPD [6]. Even in asymptomatic smokers, an increased number of inflammatory cells and structural changes in the mucosa of the airways has been reported [7]. Using computed tomography (CT) imaging, significantly thicker airway walls relative to total airway calibre have been shown in smokers without COPD compared to never-smokers [3], and among smokers with symptoms compared to those who remain asymptomatic [4]. Further, dimensions of the airway wall measured using CT in smokers are associated with development of overt COPD [8]. A better understanding of the structural changes that occur in the airway tree of smokers may provide a greater understanding of those at an increased risk of COPD.

Recently, studies have shown that the number of central airways quantified using CT (referred to as the total airway count, TAC), is significantly reduced in COPD [9], and is associated with longitudinal lung function decline [9], and with the number of terminal bronchioles measured using micro-CT of excised lung specimens [10], and therefore probably contributes to small airway pathophysiology. However, it is not known whether reduced airway count in at-risk smokers with normal spirometry is associated with development of COPD. In this study, our objective was to investigate the association of CT TAC acquired at baseline with development of COPD over 3 years in ever-smokers with normal spirometry from the multicentre population-based Canadian Cohort of Obstructive Lung Disease (CanCOLD) [11].

Methods

Study participants

The prospective, longitudinal and multicentre CanCOLD cohort study involved nine sites from six Canadian provinces [11]. Participants greater than 40 years of age were enrolled in the study by random digit dialling of the general population. At each of the nine study sites, institutional review board approval and written informed consent were obtained from all participants. Figure 1 shows a consort diagram for participant selection. Participants had Visit 1 images acquired and pulmonary function tests completed between May 2010 and August 2015. Never-smokers were defined as those with a lifetime exposure of $<1 /$ 20 pack-years. Out of $n=1561$ CanCOLD participants enrolled at Visit $1, n=466$ participants were ever-smokers (current or former smokers) without airflow limitation defined using spirometry (forced expiratory volume in $1 \mathrm{~s}\left(\mathrm{FEV}_{1}\right)$ /forced vital capacity $\left.(\mathrm{FVC})<0.70\right)$. Of these, at-risk participants without CT imaging/analysis $(n=67)$ and without follow-up $(n=83)$ were excluded; $n=316$ participants were selected for analysis. To determine whether participants developed COPD at follow-up, participants were matched at the two subsequent timepoints based on available CT imaging at baseline (Visit 1) and follow-up spirometry (Visit 2 and/or Visit 3). Because only n=198 participants had both Visit 1 and Visit 2 timepoints, and some participants had only Visit $2(n=31)$ or only Visit $3(n=87)$, we also considered participants that had any follow-up $(\mathrm{n}=316)$.

\section{Pulmonary function tests}

Spirometry was performed before and 10-15 min after inhalation of a short-acting bronchodilator according to the American Thoracic Society [12] standards to measure $\mathrm{FEV}_{1}, \mathrm{FVC}, \mathrm{FEV} \mathrm{F}_{1} / \mathrm{FVC}$ and the forced expiratory flow between $25 \%$ and $75 \%$ of the FVC $\left(\mathrm{FEF}_{25-75}\right)$. Whole body plethysmography was also performed for measurement of the residual volume (RV), total lung capacity (TLC) and the RV/TLC ratio. The diffusing capacity of the lung for carbon monoxide $\left(\mathrm{DL}_{\mathrm{CO}}\right)$ was also acquired [13].

The St George's Respiratory Questionnaire (SGRQ) was used to measure the impact on overall health, daily life and perceived well-being $[14,15]$. The COPD Assessment Test (CAT) was used to assess the global impact of COPD (cough, sputum, dyspnoea, chest tightness) on health status [16] and the modified Medical Research Council (mMRC) dyspnoea scale was used to assess degree of baseline functional disability due to dyspnoea [17].

\section{CT image acquisition and analysis}

CT images were acquired with the participant supine at suspended full inspiration and full expiration from apex to base of the lung [9, 11]. CT systems with different makes/models were used at the different sites. The CT protocol for image acquisition was: $100 \mathrm{kVp}, 50 \mathrm{mAs}, 0.5 \mathrm{~s}$ gantry rotation, pitch of 1.375 and 1.0 or 1.25 mm slice thickness, contiguous slices, and the "standard" or soft reconstruction kernel.

\section{CT image analysis}

CT image analysis was performed using commercially available software (Apollo 2.0, VIDA Diagnostics, Inc., Coralville, IA, USA). For images acquired at full expiration, CT gas trapping was quantified as the low attenuation area of the lung below -856 Hounsfield units (HU) (LAA ${ }_{856}$ ) [18]. For full-inspiration CT images, CT total air volume (TLV) and CT emphysema were quantified; CT emphysema was quantified using the LAA below $-950 \mathrm{HU}\left(\mathrm{LAA}_{950}\right)$ [19] and $-910 \mathrm{HU}\left(\mathrm{LAA}_{910}\right)$. The total airway count (TAC) 


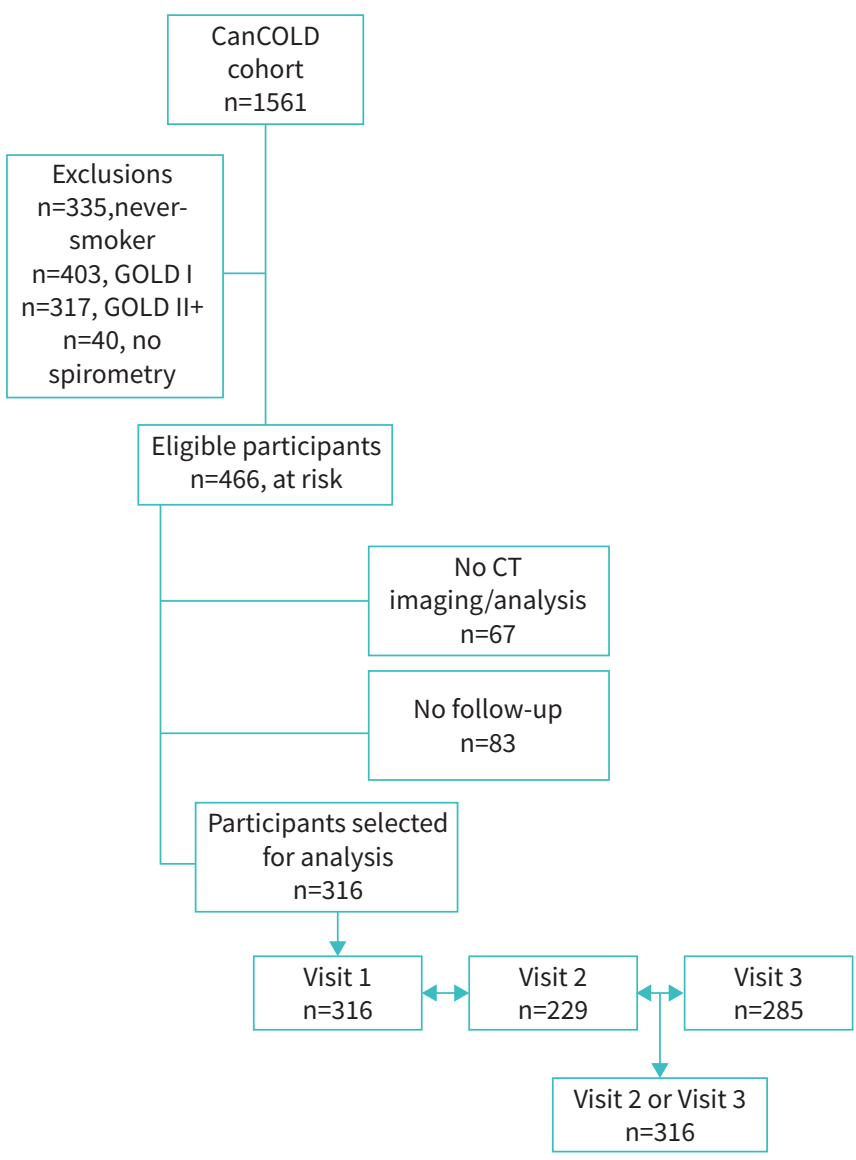

FIGURE 1 Consort diagram. There was a total of $n=1561$ Canadian Cohort Obstructive Lung Disease (CanCOLD) participants at Visit 1 . The never-smokers $(n=335)$ and participants with spirometrically-defined COPD $(n=720)$ were excluded; $n=466$ at-risk participants were eligible. Of these, at-risk participants without CT imaging/ analysis ( $n=67)$ and without follow-up at Visit 2 or Visit $3(n=83)$ were excluded. A total of 316 participants were selected for analysis. For longitudinal comparison of spirometry measurements, participants were matched at the two subsequent timepoints, Visit $2(n=229)$ and Visit $3(n=285)$. Because only $n=198$ participants had both Visit 1 and Visit 2 timepoints, and some participants had only Visit $2(n=31)$ or only Visit $3(n=87)$, we also considered participants that had any follow-up ( $n=316)$.

measurement has been previously described in detail [9]. Briefly, the airway tree was first automatically segmented, and the airway segmentation was visually verified by a highly trained analyst and edited if required. A second analyst then performed peer review of the segmentation for quality control. From the segmented and visually verified airway tree segmentation mask, the TAC measurement was obtained by summing all airway segments; a segment was defined as the section of the airway between branch points. The high repeatability of CT airway counts has been previously reported [20]. The Pi10, defined as the wall thickness of a theoretical airway with a lumen perimeter of $10 \mathrm{~mm}$, was generated [9]. The CT sub-segmental airway wall percentage was calculated as the average measurement for RB1, RB4, RB10, LB1 and LB10 airways [20].

\section{Statistical analysis}

SAS 9.4 software (Cary, NC, USA) was used for statistical analysis. Unpaired t-tests were performed for statistical comparison between at-risk participants that did or did not develop COPD at follow-up for Visit 1 participant demographic, pulmonary function and CT measurements. A Mann-Whitney test was used for groups that failed the Shapiro-Wilk normality test. For categorical variables, a Fisher's exact test was used. For the logistic regression, COPD development at Visit 2, Visit 3, the last visit (Visit 2 or 3) and at any visit (Visit 2 or 3) were the outcome variables, and CT airway measurements were the predictors, adjusted by potential confounding variables from Visit 1 including: age, sex, height, race, smoking status, pack-years, $\mathrm{FEV}_{1} / \mathrm{FVC}$, CT $\mathrm{LAA}_{950}$, CT air volume/TLC and CT model. A linear mixed effects model using the residual (restricted) maximum likelihood estimation method for the covariance parameters was performed for 
longitudinal $\mathrm{FEV}_{1}$, FVC and $\mathrm{FEV}_{1} / \mathrm{FVC}$ change with each CT airway measurement (TAC, Pi10, wall area percent, $\mathrm{LAA}_{856}$ ) included in a separate model. Time, an interaction term for time with the CT measurement, were included in the model. $\mathrm{FEV}_{1}, \mathrm{FVC}$ and $\mathrm{FEV}_{1} / \mathrm{FVC}$, and the interaction of the measurements with time, were also included in models for $\mathrm{FEV}_{1}, \mathrm{FVC}$ and $\mathrm{FEV}_{1} / \mathrm{FVC}$, respectively. Models were adjusted for age, sex, height, race, smoking status, pack-years, $\mathrm{LAA}_{950}$ and CT model. CT air volume/TLC was used for TAC, Pi10 and wall area percent and CT air volume/RV was used for LAA $_{856}$. A sensitivity analysis was also performed by adjusting multivariable regression models for self-reported history of asthma and tuberculosis.

Results

There was a total of $n=316$ ever-smokers without COPD (at risk) evaluated at baseline (Visit 1). A total of 229 participants returned for follow-up at Visit 2 and 37 participants (16\%) had spirometrically-defined COPD; a total of 285 participants returned for follow-up at Visit 3 and 54 participants (19\%) had spirometrically-defined COPD. In all 316 that returned for follow-up at Visit 2 or Visit 3, 56 participants (18\%) had spirometrically-defined COPD at their last follow-up visit. There were 19 participants that had spirometrically-defined COPD at Visit 2 but not Visit 3; the $\mathrm{FEV}_{1} / \mathrm{FVC}$ in these 19 participants was on the threshold of spirometrically-defined COPD: mean (minimum, maximum) $=73.3 \%$ (70.3\%, 74.8\%). Therefore, in addition to considering development of COPD at Visit 2, Visit 3 or the last follow-up, for selected analyses we also included whether they had spirometric COPD at any follow-up.

As shown in table 1 , there were significantly more current smokers amongst those that developed COPD $(p=0.04)$ at their last follow-up compared to those that did not develop COPD, however there were no

\begin{tabular}{|c|c|c|c|c|}
\hline $\begin{array}{l}\text { Parameter ( } \pm \text { SD unless } \\
\text { specified) }\end{array}$ & $\begin{array}{l}\text { At-risk } \\
\qquad(n=316)\end{array}$ & $\begin{array}{l}\text { No COPD at follow-up } \\
(n=260)\end{array}$ & $\begin{array}{l}\text { COPD at follow-up } \\
(n=56)\end{array}$ & $\mathrm{p}$-value \\
\hline \multicolumn{5}{|l|}{ Subject demographic } \\
\hline Age, years & $65(9)$ & $65(9)$ & $65(10)$ & 0.91 \\
\hline Female sex, n (\%) & $126(40)$ & $107(41)$ & $19(34)$ & 0.37 \\
\hline Caucasian, n (\%) & $300(95)$ & $248(95)$ & $52(93)$ & 0.50 \\
\hline Pack-years, years & $18(19)$ & $18(19)$ & $22(19)$ & 0.053 \\
\hline $\mathrm{BMI}, \mathrm{kg} \cdot \mathrm{m}^{-2}$ & $28(5)$ & $28(5)$ & $27(5)$ & 0.29 \\
\hline Height, cm & $168(9)$ & $168(9)$ & $168(10)$ & 0.87 \\
\hline Current smoker, n (\%) & $64(20)$ & $47(18)$ & $17(30)$ & 0.04 \\
\hline \multicolumn{5}{|l|}{ Pulmonary function } \\
\hline $\mathrm{FEV}_{1}, \%_{\text {pred }}$ & $99(16)$ & $99(16)$ & $96(17)$ & 0.16 \\
\hline FVC, $\%_{\text {pred }}$ & $97(16)$ & $96(15)$ & $98(17)$ & 0.32 \\
\hline $\mathrm{FEV}_{1} / \mathrm{FVC}, \%$ & $77(5)$ & $78(5)$ & $73(3)$ & $<0.0001$ \\
\hline $\mathrm{FEF}_{25-75}, \mathrm{~L}$ & $2.46(1.01)$ & $2.56(1.05)$ & $1.96(0.55)$ & $<0.0001$ \\
\hline $\mathrm{RV}, \mathrm{L}$ & $2.27(0.57)$ & $2.22(0.54)$ & $2.54(0.62)$ & 0.0005 \\
\hline TLC, L & $6.14(1.28)$ & $6.07(1.25)$ & $6.48(1.39)$ & 0.049 \\
\hline RV/TLC, \% & $37(7)$ & $37(7)$ & $40(8)$ & 0.02 \\
\hline $\mathrm{DL}_{\mathrm{CO}}, \%_{\text {pred }}$ & $111(23)$ & $112(24)$ & $109(20)$ & 0.67 \\
\hline \multicolumn{5}{|l|}{ Symptoms } \\
\hline CAT score & $5.9(5.1)$ & $6.0(4.9)$ & $5.4(5.9)$ & 0.07 \\
\hline SGRQ, total & $9.2(11.0)$ & $9.5(11.2)$ & $10.4(14.2)$ & 0.61 \\
\hline MRC & $1.3(0.5)$ & $1.2(0.5)$ & $1.4(0.7)$ & 0.21 \\
\hline \multicolumn{5}{|l|}{ Imaging } \\
\hline TLV, L & $4.48(1.08)$ & $4.40(1.05)$ & $4.84(1.19)$ & 0.005 \\
\hline TAC, $\mathrm{n}$ & $213(65)$ & $218(66)$ & $193(59)$ & 0.01 \\
\hline $\mathrm{LAA}_{910}, \%$ & $19(11)$ & $18.7(11.0)$ & $21.9(13.3)$ & 0.16 \\
\hline $\mathrm{LAA}_{950}, \%$ & $2.9(3.1)$ & $2.9(3.1)$ & $3.3(2.9)$ & 0.15 \\
\hline $\mathrm{Pi} 10, \mathrm{~mm}$ & $3.93(0.14)$ & $3.96(0.15)$ & $3.96(0.13)$ & 0.51 \\
\hline Wall area percent, \% & $65.3(2.6)$ & $65.3(2.5)$ & $65.4(2.8)$ & 0.62 \\
\hline $\mathrm{LAA}_{856}, \%$ & $18(15)$ & $18(15)$ & $20(15)$ & 0.25 \\
\hline
\end{tabular}

BMI: body mass index; FEV1: forced expiratory volume in $1 \mathrm{~s}$; \%pred: percent predicted; FVC: forced vital capacity; RV: residual volume; TLC: total lung capacity; DLCO: diffusing capacity for carbon monoxide; TAC: total airway count; $\mathrm{LAA}_{950}$ : low attenuation area of the lung with attenuation values below $-950 \mathrm{HU}$ on fullinspiration CT; Pi10: the square root of the airway wall area for a theoretical airway with $10 \mathrm{~mm}$ internal perimeter. Significance of difference : $p<0.05$. 
significant differences between those with and without COPD at follow-up for age $(\mathrm{p}=0.91)$, sex $(\mathrm{p}=0.37)$, race $(p=0.50)$, pack-years $(p=0.053)$, BMI $(p=0.29)$ or height $(p=0.87)$. At-risk participants that developed COPD at follow-up were not significantly different between those that did not develop COPD at follow-up for $\mathrm{FEV}_{1} \%_{\text {pred }}(\mathrm{p}=0.16)$, FVC\% $\%_{\text {pred }}(\mathrm{p}=0.32)$ or $\mathrm{DL}_{\mathrm{CO}} \%_{\text {pred }}(\mathrm{p}=0.67)$, however those that developed COPD at follow-up had significantly worse FEV $/$ FVC $(p<0.0001), \mathrm{FEF}_{25-75}(\mathrm{p}<0.0001)$ and RV/TLC $(p=0.02)$. There was no difference between those that did or did not develop COPD at follow-up for CAT score, SGRQ total or MRC ( $\mathrm{p}>0.05)$. For the imaging measurements, only TAC was significantly reduced in at-risk participants with COPD at follow-up $(\mathrm{p}=0.01)$, but no difference was shown for any other CT airway or emphysema measurements $(\mathrm{p}<0.05)$.

Figure 2 shows the 3D airway tree reconstructions for representative participants that did and did not develop COPD at follow-up. Participants that developed COPD show 3D airway tree reconstructions with fewer airway segments than participants that did not develop COPD at follow-up. Figure 3 shows the airway counts by generation and airway lumen diameter for participants that did not develop COPD at follow-up. As shown in figure 3a, participants that developed COPD at follow-up had significantly fewer 7th and 8th generation airways $(\mathrm{p}<0.05)$, but no other differences in the number of airways within each generation. Figure $3 \mathrm{~b}$ shows there were also significantly fewer airways with diameters that ranged between: 4.50 and $4.99 \mathrm{~mm}(\mathrm{p}<0.05), 4.00$ and $4.49 \mathrm{~mm}(\mathrm{p}<0.05), 3.50$ and $3.99 \mathrm{~mm}(\mathrm{p}<0.05)$, and 3.00 and $3.49 \mathrm{~mm}(\mathrm{p}<0.05)$, but the airways of other sizes were not significantly different.

Table 2 shows the odds ratio estimates for the development of spirometric COPD using CT measurements, and adjusting by potential confounding variables. For a 1-sD decrement in TAC the odds ratio for incident COPD increased by a factor of $1.82(\mathrm{p}=0.03)$ at Visit 3; for a 1-sD decrement in TAC the odds ratio for incident COPD at the last visit increased by a factor of $1.66(\mathrm{p}=0.03)$. There were no significant associations for Pi10, wall area percent and $\mathrm{LAA}_{856}$ with incident COPD at any follow-up timepoint. Further, CT TAC remained significantly associated with incident COPD at Visit 3 and the last visit in a multivariable regression model including $\mathrm{FEV}_{1}$ as a confounding variable $(\mathrm{p}<0.05)$.
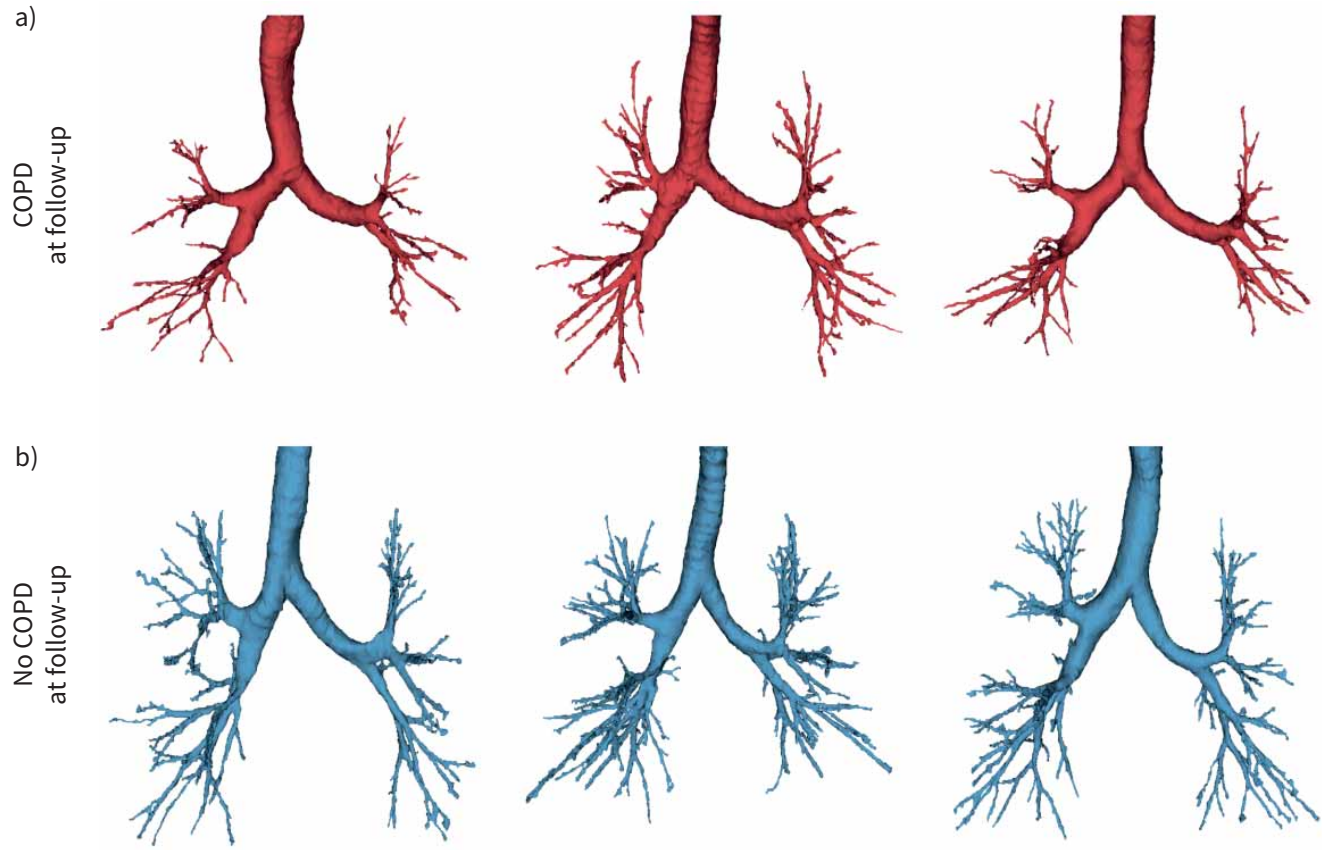

FIGURE 2 3D CT airway tree reconstructions for representative participants with (a) and without (b) COPD at follow-up. a) Left: 56 -year-old male current smoker; $B M I=25 \mathrm{~kg} \cdot \mathrm{m}^{-2}, \mathrm{FEV}_{1}=77 \%$ pred, $\mathrm{TAC}=136$. Middle: 70 -year-old male ex-smoker; $\mathrm{BMI}=29 \mathrm{~kg} \cdot \mathrm{m}^{-2}, \quad \mathrm{FEV}_{1}=101 \%$ pred, $\mathrm{TAC}=196$. Right: 54-year-old male current smoker; $\mathrm{BMI}=26 \mathrm{~kg} \cdot \mathrm{m}^{-2}, \mathrm{FEV}_{1}=99 \%$ pred, $\mathrm{TAC}=125$. b) Left: 70 -year-old female ex-smoker; $\mathrm{BMI}=22 \mathrm{~kg} \cdot \mathrm{m}^{-2}, \mathrm{FEV} \mathrm{V}_{1}=97 \%$ pred, $\mathrm{TAC}=219$. Middle: 73 -year-old male ex-smoker; $\mathrm{BMI}=26 \mathrm{~kg} \cdot \mathrm{m}^{-2}, \mathrm{FEV}_{1}=125 \%$ pred, $\mathrm{TAC}=365$. Right: 50 -year-old male ex-smoker; $\mathrm{BMI}=25 \mathrm{~kg} \cdot \mathrm{m}^{-2}, \mathrm{FEV}_{1}=96 \%$ pred, $\mathrm{TAC}=300$. BMI: body mass index; CT: computed tomography; $\mathrm{FEV}_{1}$ : forced expiratory volume in $1 \mathrm{~s}$; TAC: total airway count. 

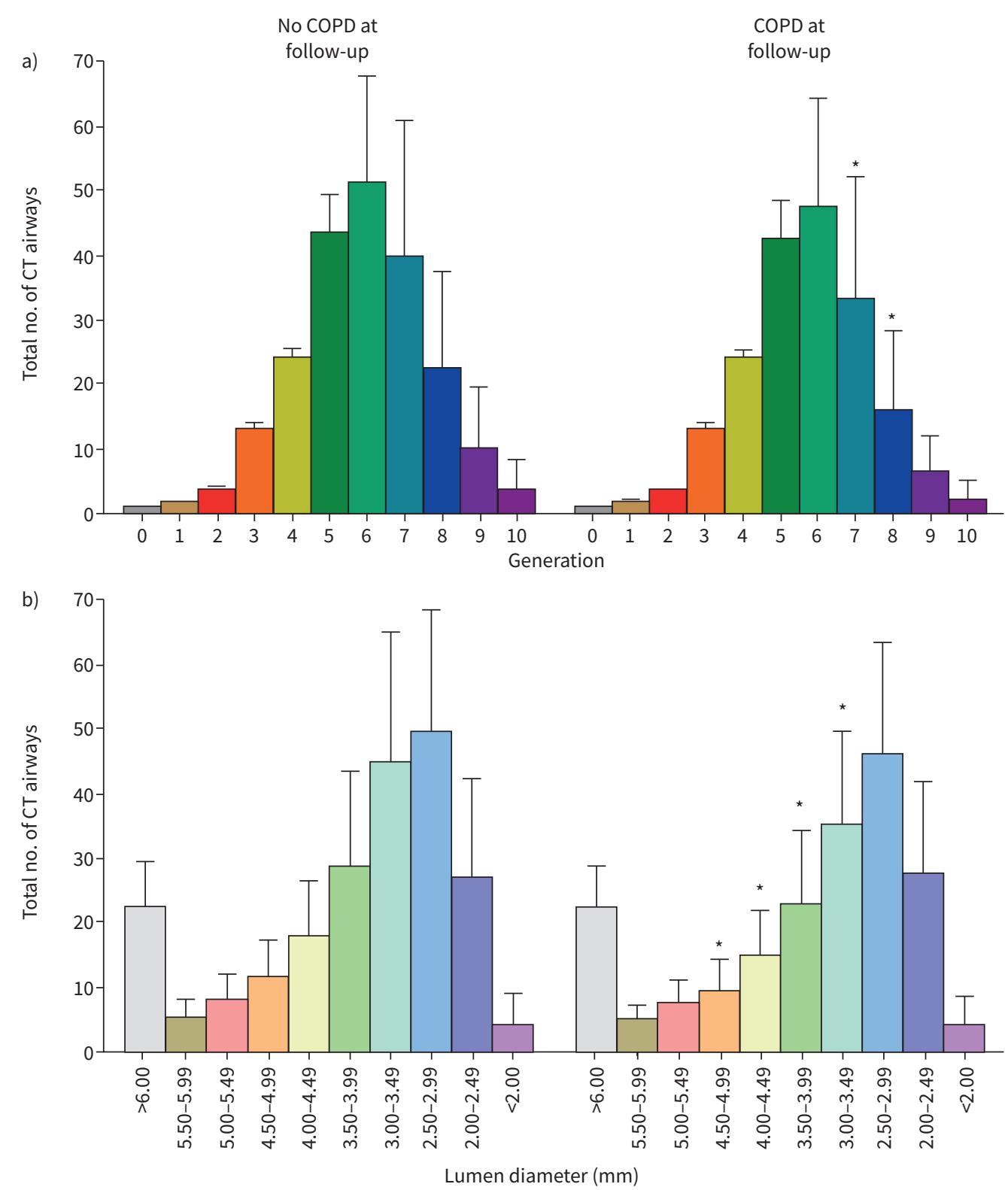

FIGURE 3 CT airway count by generation and airway lumen diameter for participants a) with COPD, and b) without COPD at follow-up. The plot summary data shows TAC measurements for airways colour coded by airway generation (a) and by various sizes divided into discrete bins (b). Error bars represent the SD of the airway counts for all participants.

Table 3 shows multivariable linear mixed effects regression models for longitudinal $\mathrm{FEV}_{1}$, FVC and $\mathrm{FEV}_{1} / \mathrm{FVC}$ decline (using the Visit 1, Visit 2 and Visit 3 timepoints) for CT airway measurements adjusted for potential baseline confounding variables. A reduced CT TAC was significantly associated with greater longitudinal decline in $\mathrm{FEV}_{1} / \mathrm{FVC}(\mathrm{p}=0.03)$, but not $\mathrm{FEV}_{1}(\mathrm{p}=0.37)$. For FVC, reduced CT TAC was associated with a reduced longitudinal decline in FVC $(p=0.03)$. Among Visit 1 measurements, sex and smoking status were not significant predictors of $\mathrm{FEV}_{1}, \mathrm{FVC}$ or $\mathrm{FEV}_{1} / \mathrm{FVC}$ decline $(\mathrm{p}>0.05)$, however smoking status was significant in the model for $\mathrm{FEV}_{1}$ decline $(\mathrm{p}=0.01)$. There were no significant associations for Pi10, wall area percent or $\mathrm{LAA}_{856}$ with longitudinal decline in $\mathrm{FEV}_{1}$, FVC or FEV $/$ FVC. CT TAC also remained significantly associated with longitudinal $\mathrm{FEV}_{1} / \mathrm{FVC}$ decline in a model including baseline $\mathrm{FEV}_{1}$, and the interaction of $\mathrm{FEV}_{1}$ with time $(\beta=0.003, \mathrm{p}=0.03)$.

To determine if the CT TAC measurement may be impacted by other respiratory diseases, we performed a sensitivity analysis adjusting for self-reported asthma and tuberculosis, as well as removing the participants 
TABLE 2 Odds ratio estimates for development of spirometric COPD

\begin{tabular}{|c|c|c|c|c|c|c|c|c|c|c|c|c|}
\hline & \multicolumn{3}{|c|}{ COPD development at Visit 2} & \multicolumn{3}{|c|}{ COPD development at Visit 3} & \multicolumn{3}{|c|}{$\begin{array}{l}\text { COPD development at last } \\
\text { visit }\end{array}$} & \multicolumn{3}{|c|}{ COPD development at any visit } \\
\hline & $\begin{array}{l}\text { Point } \\
\text { estimate }\end{array}$ & $\begin{array}{l}95 \% \\
\text { confidence } \\
\text { limits }\end{array}$ & $\mathrm{p}$-value & $\begin{array}{c}\text { Point } \\
\text { estimate }\end{array}$ & $\begin{array}{l}95 \% \\
\text { confidence } \\
\text { limits }\end{array}$ & $\mathrm{p}$-value & $\begin{array}{c}\text { Point } \\
\text { estimate }\end{array}$ & $\begin{array}{l}95 \% \\
\text { confidence } \\
\text { limits }\end{array}$ & $\mathrm{p}$-value & $\begin{array}{c}\text { Point } \\
\text { estimate }\end{array}$ & $\begin{array}{c}95 \% \\
\text { Confidence } \\
\text { limits }\end{array}$ & $\mathrm{p}$-value \\
\hline $\mathrm{N}$ & & 229 & & & 285 & & & 316 & & & 316 & \\
\hline $\begin{array}{l}\text { Time from } \\
\text { Visit } 1, \\
\text { years }( \pm \mathrm{SD})\end{array}$ & & $1.7(0.2)$ & & & $3.2(0.3)$ & & & $3.1(0.6)$ & & & $2.9(0.7)$ & \\
\hline \multicolumn{13}{|l|}{ Models" } \\
\hline TAC & 1.44 & $0.81-2.57$ & 0.21 & 1.82 & $1.14-2.92$ & 0.01 & 1.66 & $1.05-2.60$ & 0.03 & 1.45 & $0.96-2.19$ & 0.08 \\
\hline Pi10 & 0.73 & $0.45-2.28$ & 0.20 & 1.02 & $0.69-1.51$ & 0.92 & 0.95 & $0.65-1.38$ & 0.78 & 0.96 & $0.67-1.38$ & 0.84 \\
\hline $\begin{array}{l}\text { Wall } \\
\text { area } \\
\text { percent }\end{array}$ & 0.83 & $0.54-1.28$ & 0.40 & 0.96 & $0.67-1.36$ & 0.80 & 1.00 & $0.71-1.41$ & 0.99 & 0.88 & $0.64-1.23$ & 0.46 \\
\hline $\mathrm{LAA}_{856}$ & 1.34 & $0.60-2.97$ & 0.48 & 1.03 & $0.57-1.85$ & 0.92 & 0.97 & $0.54-1.72$ & 0.91 & 1.18 & $0.68-2.06$ & 0.55 \\
\hline
\end{tabular}

with asthma $(n=30)$ and tuberculosis $(n=2)$ and repeating the analysis. Multivariable logistic regression analysis showed that even after adjusting for evidence of other respiratory diseases, TAC was significantly associated with incident COPD at Visit 3 (point estimate=1.76, p=0.02) and the last visit (point estimate=1.64, $\mathrm{p}=0.03$ ). Further, when participants with reported asthma and tuberculosis were removed, TAC remained significantly associated with incident COPD at the last visit (point estimate $=1.65, p=0.04$ ). We also performed the multivariable linear mixed effects regression model that adjusted for potential baseline confounding variables, including asthma and tuberculosis, and showed reduced TAC remained statistically significantly associated with longitudinal decline in $\mathrm{FEV}_{1} / \mathrm{FVC}$ (stand. $\beta=0.003, \mathrm{p}=0.03$ ) and FVC (stand. $\beta=-0.18, p=0.02$ ).

TABLE 3 Mixed effects multivariable regression models for longitudinal $\mathrm{FEV}_{1}, \mathrm{FVC}$ and $\mathrm{FEV}_{1} / \mathrm{FVC}$ change with CT measurements

\begin{tabular}{|c|c|c|c|}
\hline Interactions & Estimate $(95 \% \mathrm{Cl})$ & $\mathrm{SE}$ & $\mathrm{p}$-value \\
\hline \multicolumn{4}{|l|}{$\mathrm{FEV}_{1}, \mathrm{~mL}$} \\
\hline TAC $\times$ time & -0.052 & 0.058 & 0.37 \\
\hline Pi10×time & -15.80 & 25.14 & 0.53 \\
\hline Wall area percent $\times$ time & -0.70 & 1.40 & 0.62 \\
\hline $\mathrm{LAA}_{856} \times$ time & -0.32 & 0.26 & 0.22 \\
\hline \multicolumn{4}{|l|}{ FVC, $\mathrm{mL}$} \\
\hline TAC×time & -0.18 & 0.08 & 0.02 \\
\hline Pi10×time & -42.37 & 36.00 & 0.24 \\
\hline Wall area percent $\times$ time & 0.73 & 1.97 & 0.71 \\
\hline $\mathrm{LAA}_{856} \times$ time & -0.36 & 0.36 & 0.33 \\
\hline \multicolumn{4}{|l|}{$\mathrm{FEV}_{1} / \mathrm{FVC}, \%$} \\
\hline TAC×time & 0.003 & 0.001 & 0.03 \\
\hline Pi10×time & -0.67 & 0.49 & 0.17 \\
\hline Wall area percent $\times$ time & -0.03 & 0.03 & 0.33 \\
\hline LAA $_{856} \times$ time & -0.002 & 0.005 & 0.75 \\
\hline
\end{tabular}


Discussion

Structural changes to the airways occur in smokers [3, 4, 6, 7], and even young smokers [21], despite the fact that only 25-30\% of those that smoke go on to develop COPD [1, 2]. Therefore, a better understanding of the pre-clinical changes that occur in the airway tree is required and may help identify those at an increased risk of developing COPD. Based on previous studies demonstrating the CT TAC is related to lung function decline [9] and reflects the loss and remodelling of the terminal bronchioles as measured using micro-CT of lung specimens [10], we aimed to determine whether CT TAC was associated with incident COPD in at-risk ever-smokers. We report: 1) CT TAC was significantly reduced in at-risk participants that developed COPD at follow-up compared to those that did not develop COPD, but there were no differences for other CT measurements, and this reduction in airway number occurred in the smaller airways; 2) at-risk participants with reduced TAC had an approximately two-times increased risk of developing incident COPD; and 3) reduced TAC was significantly associated with greater longitudinal $\mathrm{FEV}_{1} / \mathrm{FVC}$ decline.

Here we have shown that at-risk participants that develop overt COPD have reduced airway count on CT compared to those that do not develop COPD during the follow-up interval, and that the decline in airway count is driven primarily by a reduction in the smaller airways (7th and 8th generation). Interestingly, when the number of airways was stratified by lumen diameter, we showed that this decline occurred in airways $3.00-4.50 \mathrm{~mm}$ in diameter, but there were no significant changes in the number of airways $<3.00 \mathrm{~mm}$ in diameter. Taken together, this may suggest that while there are fewer small airways (7th and 8th generation), there are also fewer mid-sized airways, which may suggest narrower lumen diameters.

Interestingly, we showed no difference in symptoms between those that developed COPD at follow-up compared to those that did not develop COPD, and this may be due to the lower symptom burden in the population-based CanCOLD sample. An important advantage of population-based studies is they can minimise bias of symptom burden among ever-smokers without COPD when compared with other study bases, where participants may be more likely to enrol due to their symptoms. It has been shown that bronchial biopsy specimens of asymptomatic smokers without COPD have increased thickness of the tenascin and lamina layers, and decreased structural integrity of the epithelial layers compared to never-smokers [7]. These structural changes in the airway walls have also been correlated with the number of mast cells in the epithelium, lamina propria and smooth muscle in asymptomatic smokers, but not never-smokers [22]. Taken together, these findings suggest that airway remodelling occurs in smokers, even those that remain asymptomatic, and that reduced CT airway count may identify individuals at risk of developing COPD.

We also demonstrated that reduced airway count on CT in at-risk smokers with normal lung function at baseline was associated with an increased risk of developing spirometrically-defined COPD over a relatively short duration follow-up. Oelsner and colleagues [8] investigated participants from the Multi-Ethnic Study of Atherosclerosis (MESA) study [23] and showed that in participants with normal spirometry, increased CT Pi10 at baseline predicted increased risk of incident spirometry-defined COPD over 5 years. In our study, we did not find that Pi10 was able to predict incident COPD. This may be due to the smaller number of subjects included in our study with follow-up, and the shorter follow-up duration. We do note that for TAC, the odds ratio for COPD development at Visit 3 ( $3.2 \pm 0.3$ years) was significant, while it was not significant at Visit 2 (1.7 \pm 0.2 years).

We also demonstrated that CT TAC was associated with longitudinal decline in $\mathrm{FEV}_{1} / \mathrm{FVC}$ and FVC, but not $\mathrm{FEV}_{1}$ over an approximately 3 -year follow-up in this at-risk group. The finding that the $\mathrm{FEV}_{1} / \mathrm{FVC}$ ratio is declining at a faster rate, while FVC declines at a lower rate, in those with reduced TAC may suggest a disproportionate fall in $\mathrm{FEV}_{1}$ relative to the FVC. In other words, in participants with higher TAC, $\mathrm{FEV}_{1}$ and FVC fall in parallel, and therefore the $\mathrm{FEV}_{1} / \mathrm{FVC}$ ratio remains constant over time, whereas in those with reduced TAC, the $\mathrm{FEV}_{1}$ and $\mathrm{FVC}$ fall at different rates, resulting in a decline in the $\mathrm{FEV}_{1} / \mathrm{FVC}$ ratio. Although we have previously demonstrated that CT TAC is significantly associated with longitudinal decline in $\mathrm{FEV}_{1}$, this study included COPD participants [9]. Nevertheless, our results indicate that at-risk participants with reduced CT TAC are more likely to have a decline in their $\mathrm{FEV}_{1} / \mathrm{FVC}$ ratio in a short period of time.

This study is strengthened by the relatively large number of at-risk smokers included due to the population study design of CanCOLD [11], and the short duration follow-up intervals investigated. We must acknowledge, however, that it remains unclear whether the lower airway count is due solely to smoking-related pathologies, such as increased number of inflammatory cells and structural changes to the airway wall components [7, 24]. An alternative explanation is that low TAC is, at least in part, due to the 
inherent airway tree structure. Individuals not exposed to traditional COPD risk factors, such as smoking, who exhibited dysanapsis on CT, i.e. small airways relative to their lung size, have been shown to have an increased risk of developing COPD [25]. We note that dysanapsis on CT is thought to be a measure of inherent airway tree structure, measured as the mean airway lumen diameter divided by the total lung volume, while CT TAC is thought to reflect the remodelling/loss of airways. An advantage of CT TAC is that it may reflect airway wall thickening and airway lumen narrowing, as well as airway destruction. A limitation of this study is that we do not know if these participants have a history of being premature or had low weight at birth, which may contribute to development of COPD and could potentially be associated with CT TAC. Long-term studies in children or young adults are required to determine if airway tree structural variability is exhibited early in life, and if reduced airway counts are associated with increased risk of developing lung disease.

We also note that the CT TAC measurement has yet to be investigated longitudinally, either in the short term to assess measurement reproducibility, or longer term to determine whether TAC decreases over time with disease progression, or if TAC increases in response to treatment. Investigating CT TAC measurements longitudinally in COPD participants is an important goal of future studies. We also acknowledge that it is important to investigate the risk of COPD progression in former versus current smokers, as well as in males versus females, separately, to provide a better understanding of differences in longitudinal lung function decline in these groups, and, possibly, the potential for personalised risk assessment. It is also important for future studies to investigate the association between CT airway measurements with longitudinal decline in body plethysmography and diffusion capacity measurements, particularly RV and RV/TLC. Another limitation is that there are other nondisease-related factors that may impact the TAC measurement. Other factors, such as lung volume during image acquisition [26], field of view [27], and others [28], have been shown to influence airway measurements. We acknowledge that even with standardised image acquisition parameters, the image quality may differ with different CT systems $[26,28]$, resulting in variability in the CT measurements. Although airway phantoms can assess the calibration of several CT scanner parameters, and may be used to correct for measurement bias between each scanner [29], no phantoms were used in this study. Importantly, there is currently no consensus on standardised airway phantoms. Reducing CT airway measurement variability is an important goal, and groups such as the Quantitative Imaging Biomarkers Alliance (QIBA) are developing guidelines for standardised image acquisition protocols for multicentre studies. In this study, to minimise the impact of these factors we used a standardised image acquisition protocol and breath-hold coaching [30], and we have adjusted for these potentially confounding variables in our models. Finally, we also acknowledge that due to the relatively short duration of follow-up, only 56 (18\%) of participants became (incident) COPD. This number would probably increase over a longer duration of follow-up. Future studies using longer duration follow-ups should be performed to confirm these findings. Nevertheless, our findings indicate that CT TAC was significantly and independently associated with developing incident COPD and longitudinal $\mathrm{FEV}_{1} / \mathrm{FVC}$ decline, and can therefore provide a greater understanding of the pathology that may influence $\mathrm{FEV}_{1} / \mathrm{FVC}$.

In conclusion, we showed that participants with reduced CT total airway count had a two-times higher risk for developing COPD, and reduced TAC was significantly associated with accelerated longitudinal $\mathrm{FEV}_{1} /$ FVC decline. These findings add to a growing body of evidence that smokers exhibit early structural changes associated with COPD prior to abnormal spirometry, and suggests CT TAC is a potential tool to help identify smokers at increased risk of COPD.

Acknowledgements: The authors would like to thank the men and women who participated in the study and individuals in the CanCOLD Collaborative Research Group: Jonathon Samet (Keck School of Medicine of USC, Los Angeles, CA, USA); Milo Puhan (John Hopkins School of Public Health, Baltimore, MD, USA); Qutayba Hamid, Carolyn Baglole, Palmina Mancino, Pei-Zhi Li, Zhi Song, Dennis Jensen, Benjamin McDonald Smith (McGill University, Montreal, QC, Canada); Yvan Fortier and Mina Dligui (Sherbrooke University, Sherbrooke, QC, Canada); Kenneth Chapman, Jane Duke, Andrea S. Gershon, Teresa To (University of Toronto, Toronto, ON, Canada); J. Mark Fitzgerald, Mohsen Sadatsafavi (University of British Columbia, Vancouver, BC, Canada); Christine Lo, Sarah Cheng, Elena Un, Michael Cheng, Cynthia Fung, Nancy Haynes, Liyun Zheng, LingXiang Zou, Joe Comeau, Jonathon Leipsic, Cameron Hague (UBC James Hogg Research Center, Vancouver, BC, Canada); Brandie L. Walker, Curtis Dumonceaux (University of Calgary, Calgary, AB, Canada); Paul Hernandez, Scott Fulton (University of Dalhousie, Halifax, NS, Canada); Shawn Aaron, Kathy Vandemheen (University of Ottawa, Ottawa, ON, Canada); Denis O’Donnell, Matthew McNeil, Kate Whelan (Queen's University, Kingston, ON, Canada); Francois Maltais, Cynthia Brouillard (University of Laval, Quebec City, QC, Canada); Darcy Marciniuk, Ron Clemens, Janet Baran (University of Saskatchewan, Saskatoon, SK, Canada). 
Provenance: Submitted article, peer reviewed.

Conflict of interest: M. Kirby reports consultancy for VIDA Diagnostics Inc., outside the submitted work. B.M. Smith reports grants from the Canadian Institutes of Health Research (CIHR), the National Institutes of Health (USA), the McGill Interdisciplinary Initiative in Infection and Immunity (MI4), the Research Institute of the McGill University Health Centre (MUHC), the Quebec Lung Association, and the Quebec Health Research Fund, outside the submitted work. N. Tanabe reports grants from FUJIFILM, and personal fees from AstraZeneca, Boehringer Ingelheim and GlaxoSmithKline, outside the submitted work. J.C. Hogg has nothing to disclose. H.O. Coxson has nothing to disclose. D.D. Sin reports personal fees from AstraZeneca, Boehringer Ingelheim and Grifols, outside the submitted work. J. Bourbeau reports grants from CIHR and the Canadian Respiratory Research Network, personal fees from the Canadian Thoracic Society and CHEST, grants from the Foundation of the MUHC and Aerocrine, and grants and personal fees from AstraZeneca, Boehringer Ingelheim, Grifols, GlaxoSmithKline, Novartis and Trudell, outside the submitted work. W.C. Tan reports grants from the CIHR (CIHR/Rx\&D Collaborative Research Program Operating Grants, 93326) with industry partners AstraZeneca Canada Ltd, Boehringer Ingelheim Canada Ltd, GlaxoSmithKline Canada Ltd, Merck, Novartis Pharma Canada Inc., Nycomed Canada Inc. and Pfizer Canada Ltd, during the conduct of the study; and personal fees from GlaxoSmithKline, Canada, and AstraZeneca, Canada, outside the submitted work.

Support statement: M. Kirby gratefully acknowledges salary support from the Parker B. Francis Fellowship Program and the Canada Research Chair Program (Tier II), and funding support from the Natural Sciences and Engineering Research Council of Canada (NSERC) Discovery Grant. H.O. Coxson was a Roberta R. Miller Fellow in Thoracic Imaging from the British Columbia Lung Association. We acknowledge the Canadian Institute of Health Research (CIHR/Rx\&D Collaborative Research Program Operating Grants, 93326); the Respiratory Health Network of the FRQS; the Canadian Respiratory Research Network; the Canadian Lung Association/Canadian Thoracic Society; British Columbia Lung Association; and industry partners including AstraZeneca Canada Inc., Boehringer Ingelheim Canada Inc., GlaxoSmithKline Canada Inc., Merck, Novartis Pharma Canada Inc., Nycomed Canada Inc. and Pfizer Canada Ltd for funding support. Funding information for this article has been deposited with the Crossref Funder Registry.

\section{References}

1 Løkke A, Lange P, Scharling H, et al. Developing COPD: a 25 year follow up study of the general population. Thorax 2006; 61: 935-939.

2 Pelkonen M, Notkola IL, Nissinen A, et al. Thirty-year cumulative incidence of chronic bronchitis and COPD in relation to 30-year pulmonary function and 40-year mortality: a follow-up in middle-aged rural men. Chest 2006; 130: 1129-1137.

3 Regan EA, Lynch DA, Curran-Everett D, et al. Clinical and radiologic disease in smokers with normal spirometry. JAMA Intern Med 2015; 175: 1539-1549.

4 Woodruff PG, Barr RG, Bleecker E, et al. Clinical significance of symptoms in smokers with preserved pulmonary function. N Engl J Med 2016; 374: 1811-1821.

5 Tan WC, Bourbeau J, Hernandez P, et al. Exacerbation-like respiratory symptoms in individuals without chronic obstructive pulmonary disease: results from a population-based study. Thorax 2014; 69: 709-717.

6 Stämpfli MR, Anderson GP. How cigarette smoke skews immune responses to promote infection, lung disease and cancer. Nat Rev Immunol 2009; 9: 377-384.

7 Amin K, Ekberg-Jansson A, Löfdahl CG, et al. Relationship between inflammatory cells and structural changes in the lungs of asymptomatic and never smokers: a biopsy study. Thorax 2003; 58: 135-142.

8 Oelsner EC, Smith BM, Hoffman EA, et al. Prognostic significance of large airway dimensions on computed tomography in the general population: the Multi-Ethnic Study of Atherosclerosis (MESA) lung study. Ann Am Thorac Soc 2018; 15: 718-727.

9 Kirby M, Tanabe N, Tan WC, et al. Total airway count on computed tomography and the risk of chronic obstructive pulmonary disease progression. Findings from a population-based study. Am J Respir Crit Care Med 2018; 197: 56-65.

10 Kirby M, Tanabe N, Vasilescu DM, et al. Computed tomography total airway count is associated with the number of micro-computed tomography terminal bronchioles. Am J Respir Crit Care Med 2020; 201: 613-615.

11 Bourbeau J, Tan WC, Benedetti A, et al. Canadian Cohort Obstructive Lung Disease (CanCOLD): fulfilling the need for longitudinal observational studies in COPD. COPD 2014; 11: 125-132.

12 Miller MR, Hankinson J, Brusasco V, et al. Standardisation of spirometry. Eur Respir J 2005; 26: 319-338.

13 Wanger J, Clausen JL, Coates A, et al. Standardisation of the measurement of lung volumes. Eur Respir J 2005; 26: 511-522.

14 Jones PW, Quirk FH, Baveystock CM, et al. A self-complete measure of health status for chronic airflow limitation. The St. George's Respiratory Questionnaire. Am Rev Respir Dis 1992; 145: 1321-1327.

15 Jones PW, Quirk FH, Baveystock CM. The St George's Respiratory Questionnaire. Respir Med 1991; 85: 25-31. 
16 Jones PW, Harding G, Berry P, et al. Development and first validation of the COPD Assessment Test. Eur Respir J 2009; 34: 648-654.

17 Mahler DA, Wells CK. Evaluation of clinical methods for rating dyspnea. Chest 1988; 93: 580-586.

18 Jain N, Covar RA, Gleason MC, et al. Quantitative computed tomography detects peripheral airway disease in asthmatic children. Pediatr Pulmonol 2005; 40: 211-218.

19 Gevenois PA, Zanen J, de Maertelaer V, et al. Macroscopic assessment of pulmonary emphysema by image analysis. J Clin Pathol 1995; 48: 318-322.

20 Smith BM, Hoffman EA, Rabinowitz D, et al. Comparison of spatially matched airways reveals thinner airway walls in COPD. The Multi-Ethnic Study of Atherosclerosis (MESA) COPD Study and the Subpopulations and Intermediate Outcomes in COPD Study (SPIROMICS). Thorax 2014; 69: 987-996.

21 Niewoehner DE, Kleinerman J, Rice DB. Pathologic changes in the peripheral airways of young cigarette smokers. N Engl J Med 1974; 291: 755-758.

22 Ekberg-Jansson A, Amin K, Bake B, et al. Bronchial mucosal mast cells in asymptomatic smokers relation to structure, lung function and emphysema. Respir Med 2005; 99: 75-83.

23 Multi-Ethnic Study of Atherosclerosis (MESA) COPD Study. www.cumc.columbia.edu/dept/medicine/ generalmed/epi_copd.htm.

24 Hogg JC, Chu F, Utokaparch S, et al. The nature of small-airway obstruction in chronic obstructive pulmonary disease. N Engl J Med 2004; 350: 2645-2653.

25 Smith BM, Kirby M, Hoffman EA, et al. Association of dysanapsis with chronic obstructive pulmonary disease among older adults. JAMA 2020; 323: 2268-2280.

26 Zach JA, Newell JD, Schroeder J, et al. Quantitative computed tomography of the lungs and airways in healthy nonsmoking adults. Invest Radiol 2012; 47: 596-602.

27 Sheshadri A, Rodriguez A, Chen R, et al. Effect of reducing field of view on multidetector quantitative computed tomography parameters of airway wall thickness in asthma. J Comput Assist Tomogr 2015; 39: 584-590.

28 Oguma T, Hirai T, Niimi A, et al. Limitations of airway dimension measurement on images obtained using multi-detector row computed tomography. PLOS ONE 2013; 8: 76381.

29 Robinson TE, Long FR, Raman P, et al. An airway phantom to standardize CT acquisition in multicenter clinical trials. Acad Radiol 2009; 16: 1134-1141.e1.

30 Sieren JP, Newell JD Jr, Barr RG, et al. SPIROMICS protocol for multicenter quantitative computed tomography to phenotype the lungs. Am J Respir Crit Care Med 2016; 194: 794-806. 